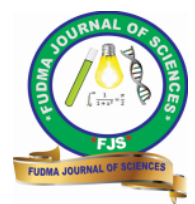

FUDMA Journal of Sciences (FJS)

ISSN online: $2616-1370$

ISSN print: 2645 - 2944

Vol. 4 No. 3, September, 2020, pp $343-350$

DOI: https://doi.org/10.33003/fjs-2020-0403-342

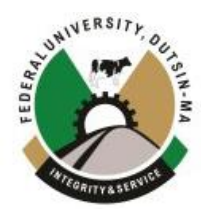

\title{
LEVEL OF AWARENESS, ACCESS AND USE OF LONG LASTING INSECTICIDAL NETS (LLINS) IN FIVE PUBLIC HEALTH CENTRES WITHIN KADUNA METROPOLIS
}

\author{
${ }^{1}$ Yayock, H. C., ${ }^{2}$ Osageide, N. O., ${ }^{1}$ Mande, H., ${ }^{1}$ Habib, H. and ${ }^{1}$ Zamani, J. \\ ${ }^{1}$ Department of Biological Sciences, Faculty of Science, Kaduna State University, Kaduna State, Nigeria \\ ${ }^{2}$ College of Agriculture and Animal Science, Mando, Kaduna Ahmadu Bello University. \\ Corresponding Author's email: yayockhosea2000@yahoo.com, +2348053370180
}

\begin{abstract}
A cross sectional study designed to assess the difference in level of Awareness, Access and Use of Long Lasting Insecticidal Nets (LLINs) from consenting pregnant women aged between 15 to 40 years attending routine ante-natal clinic sessions at Kaduna State University (Barau Dikko) Teaching Hospital, General Hospital Kawo, Primary Health Care Badarawa, Primary Health Care Angwan Romi and General Hospital Sabon Tasha. A total of 360 questionnaires were distributed, but only 308 returned completed. Also, mosquito samples were collected in 30 randomly selected households of the consenting pregnant women that were within three kilometer radius range of the antenatal clinic for 12 weeks' period. A one-way ANOVA was conducted using SPSS statistical package version 22. The result revealed that there was no significant difference $(\mathrm{P}>0.05)$ in level of Awareness (92.53\%), Access (75.32\%) and Use (67.86\%) of Long Lasting Insecticidal Nets (LLINs) among the pregnant women attending the various ante-natal hospitals/primary health care facilities. A total of 344 larvae samples were encountered and identified as Culex species 259(75.29\%) and Aedes species 85(24.71\%). Awareness, Access and Use of LLINs is relatively similar; while the mosquito species are vectors of Filariasis, Yellow fever, Dengue fever and can be prevented by the use of LLINs.
\end{abstract}

Keywords: Kaduna Metropolis, LLINs Awareness, Access and Use, Mosquito Preventive Measures.

\section{INTRODUCTION}

Long Lasting Insecticidal Nets (LLINs) are effective in the prevention of malaria, (WHO, 2005). Malaria is a lifethreatening disease caused by protozoan, plasmodium parasite transmitted via an infected female Anopheles mosquito from one person to another (WHO, 2017). About 3.2 billion people were at risk of the disease in 97 countries, territories and areas in 2018, and an estimated 228 million cases occurred. Currently, the disease killed about 405, 000 people, mostly children aged under 5 years in sub-Saharan Africa, (WHO, 2019).

The disease remains endemic in all six WHO regions and the burden is heaviest in the African region, where an estimated $90 \%$ of all malaria deaths occur. Two countries - the Democratic Republic of the Congo and Nigeria - account for about $40 \%$ of estimated mortality due to malaria worldwide (WHO, 2019). Around the world, millions of people remain without access to malaria prevention and treatment, and most cases and deaths go unregistered and unreported. Given the projected growth in the size of the world's population by 2030 , more people will be living in countries where malaria is a risk, putting further strain on health systems and national malaria programme budgets, (WHO, 2016). Reports indicates that 578 million Insecticide-Treated Mosquito Nets (ITNs) also called Long Lasting Insecticidal Nets (LLINs) were distributed between 2016 and 2018 in the African region, with $10 \%$ of these nets in ante-natal care facilities, (WHO,2019).

LLINs was introduced in Nigeria as an effective means of preventing mosquito bites, malaria infection and reducing associated morbidity and mortality, particularly in endemic areas, (Okoye and Isara, 2011). Nigeria, which has a tropical climate, with its high average annual rainfall provides ideal conditions for mosquito breeding and malaria transmission throughout the country, (NiMET, 2016). The country has the highest malaria burden in the world and the disease is one of the top causes of morbidity and mortality nationally thus; it led to the distribution of 24 million Insecticide-Treated Nets (ITNs) and nine million Artemisinin-based Combination Therapy (ACT) treatment courses distributed in 2016, (Global Fund, 2018). Presently there are reports that about 11 million pregnant women were exposed to malaria infections in 2019 due to non-use or improper use of insecticide-treated mosquito nets, (WHO, 2019).

According to a report in 2015, Kaduna state Archdiocesan Catholic Health Care Initiative (ACHI) in collaboration with Christian Aid Nigeria, distributed 15,000 LLINs to some communities in Kajuru local government area. The gesture was aimed at complementing the state government's efforts towards eradicating malaria in the state, (ACHI, 2015). The Malaria Control Unit in Kaduna State stated that, "Malaria is preventable and curable; however, it is still a major cause of deaths in children under five years, pregnant women, HIV/AIDS patients and non-immune migrants, all of which are more susceptible to the disease" (MCU Kaduna, 2017).

The objectives of reducing the disease burden and eliminating malaria are in tandem to several of the sustainable development goals, (Anonymous, 2018). Pregnancy reduces a woman's immunity, making pregnant women more susceptible to 
malaria infection and increasing the risk of illness, anaemia, severe disease and death, (Okeibunor et al., 2012). For the unborn child, maternal malaria increases the risk of spontaneous abortion, stillbirth, premature delivery and low birth weight - a leading cause of child mortality, (WHO, 2018). Evidence shows that in malaria-endemic areas, sleeping under mosquito nets treated with an insecticide is beneficial to the health of the pregnant woman, her fetus and the newborn infant, (Oyedeji et al., 2009; Adeogun et al., 2012; Ezeigbo et al., 2016). Long-Lasting Insecticidal Nets (LLINs) are designed to maintain their effectiveness against mosquitoes that carry malaria and other diseases for at least three years. They have been identified as a relatively cheap and acceptable method of reducing malaria cases but several individuals and regions have factors that determine compliance and effective use of these nets (WHO, 2018).

Although LLINs enables reduction in malaria cases and mortality; the problem of non-use, availability and mosquito insecticide resistance remains a major challenge to the fight against malaria, (Corbel et al., 2010; WHO, 2018). Household ownership of at least two LLINs, prevention and treatment of malaria in pregnancy is one of the three core interventions of National Malaria Control Strategic Plan which focuses on the objective of increasing LLIN use to $80 \%$, $(\mathrm{FMoH}, 2014)$.

The ownership and utilization of LLINs vary among individuals and communities; hence the need to ascertain the level of awareness, ownership, maintenance and utilization of LLINs among susceptible population of pregnant women attending antenatal clinic in selected Primary Health Care Units and General Hospitals within Kaduna metropolis. This is with the view to increase possession and use of ITNs or long-lasting insecticidal nets (LLINs), especially among children under 5 years and pregnant women, thereby reducing malaria cases and mortality.

Thus, the study aimed at assessing compliance with the level of use of LLINs during pregnancy and also to encourage compliance or the use of LLINs in house-holds, thereby reducing malaria burdens and death in Kaduna metropolis.

\section{MATERIAL AND METHODS}

Study area.

The study was conducted at five selected government health care units across the three local government areas (Chukun, Kaduna North and Kaduna South) make Kaduna metropolis. The health facilities chosen were; Kaduna State University (Barau Dikko) Teaching Hospital $\left(10.5102^{\circ} \mathrm{N} ; 7.4405667^{\circ} \mathrm{E}\right)$, here referred to as KASU BDTH; General Hospital Kawo $\left(10^{\circ} 58^{\prime} 21.052^{\prime \prime} \mathrm{N} ; 7^{\circ} 45^{\prime} 62.87^{\prime} \mathrm{E}\right)$, here referred to as GENH KAWO; Primary Health Care Badarawa; (10³3'34.2N; $7^{\circ} 27^{\prime} 13.32 \mathrm{E}$ ), here referred to as PHC BADW; Primary Health Care Angwan Romi $\left(10.92565^{\circ} \mathrm{N} ; 8.01900^{\circ}\right)$ here referred to as PHC ROMI; and General Hospital Sabon Tasha $\left(10.43479^{\circ}\right.$; $7.41821^{\circ}$ ), here referred to as GENH SABO; (Fig.1).

Kaduna metropolis is located in a tropical continental climate with distinct wet and dry seasons. The metropolis vegetation comprising savannah grassland with scattered trees and woody shrubs, (Ndabula et al., 2014).

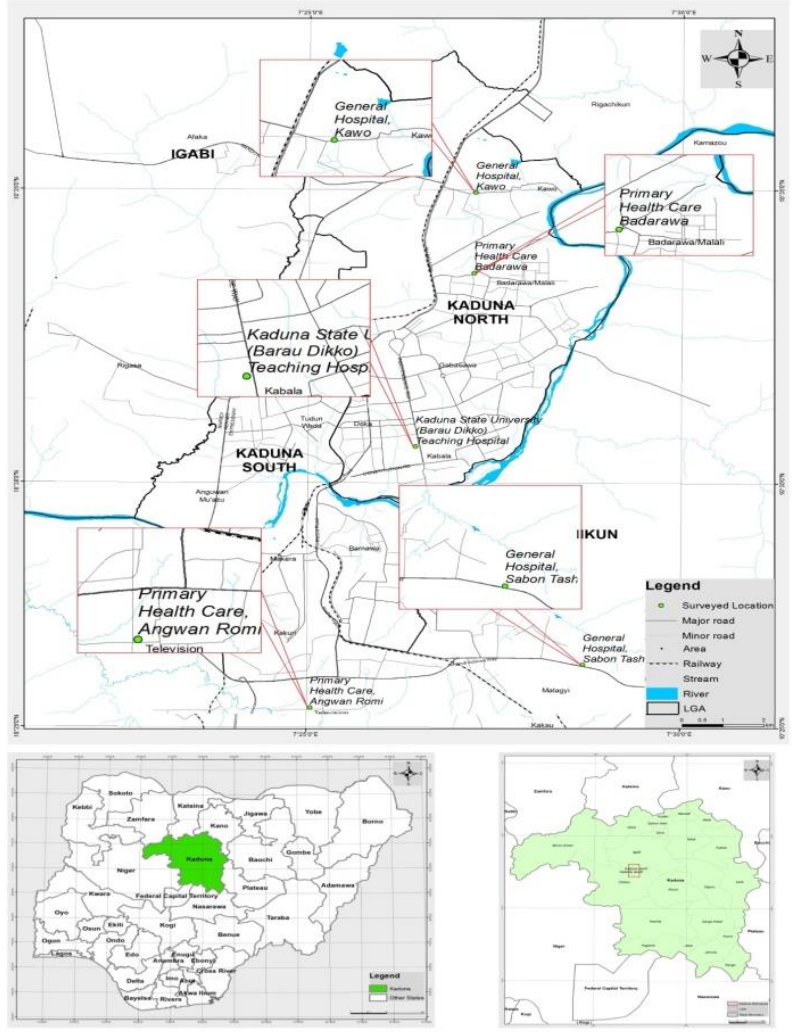

Fig.1. Kaduna Metropolis. (Source. 2018 www.linkbola.co; ganajosiah@google.com) 


\section{Sampling.}

Sampling using designed cross sectional study questionnaires was conducted from February 2017 - November 2017. Each month 40 questionnaires were distributed to consenting pregnant women aged between 15 to 40 years who were attending routine ante-natal clinic sessions at any of the above health facilities. Also sampling of mosquito larvae according to (Adebote et al., 2006) was conducted randomly at five houses each within 3 kilometre radius of any of the health centre. The mosquito larvae were collected using plastic rubber soup ladle of $8 \mathrm{~cm}$ in diameter, $30 \mathrm{~cm}$ long from stagnant or standing waters in pools, gutters or house hold containers. The immature stages were separated into larvae and pupae, then poured through a fine sieve of $0.5 \mathrm{~mm}$ mesh size to concentrate them. They were then preserved in $70 \%$ ethanol in covered labeled specimen tubes, (Service, 1976). All samples were carefully transported to the laboratory of Department of Biological Sciences Kaduna State University, Kaduna for identification. Identification of mosquito larvae was done to genus level only using the Olympus dissecting microscope with objective lens of $10 \mathrm{X}$ and $20 \mathrm{X}$ with the guide of the pictorial keys by Hopkins (1952) and Gillies \& Coetzee (1987). The species identified and settlement areas were noted.

\section{Ethical consent.}

All participants provided informed consent for participation in this research. The study was considered and approved by Students' Project Committee, Department of Biological Sciences Kaduna State University and the Barau Dikko Teaching Hospital Health Research Ethics Committee (BDTH HREC); Kaduna State University on behalf of the Kaduna State Ministry of Health and Human Resources, (See attached as appendix A).

\section{Statistical Analyses.}

A one-way ANOVA was conducted at 0.05 level of significance using SPSS statistical package version 22 to reveal significant difference in level of Awareness, Access and Use of Long Lasting Insecticidal Nets (LLINs) among pregnant patients attending five health care facilities in Kaduna metropolis. Also, percentages shown in bar charts and a table were used to express the socio demographic information of the respondents.

\section{RESULTS}

A total of 360 questionnaires were distributed only $308(85.55 \%)$ returned completed, (Table 1). The sociodemographic characteristics revealed the highest (31.81\%) number of the respondents to be in age bracket 20 to 24 years; while the least $(9.09 \%)$ were aged between 35 to 40 years. Respondents' level of education and occupational status varied across the five health facilities; with primary education level $(38.96 \%)$ being prevalent followed by secondary education (31.82\%). Pregnant women civil servants $(21.75 \%)$ attended antenatal care more at KASU BDTH than any of the other facilities, (Table 1).

The mosquito larvae encountered and identified from the 30 house-holds of selected or consenting respondents who reside about $3 \mathrm{Km}$ radius to the PHC facility or Hospital revealed only two species. Culex species $(74.3 \%)$ was more prevalent than Aedes species (24.7\%). Anopheles species which transmits malaria parasites was absent during the period of study, (Table 2).

The level of Awareness, Access and Use of LLINs by age groups and across the five health centres are expressed as shown in the figures below, (Figures $1 \& 2$ ).

Table 1. Socio-demographic characteristics of respondents in the five health centres within Kaduna metropolis.

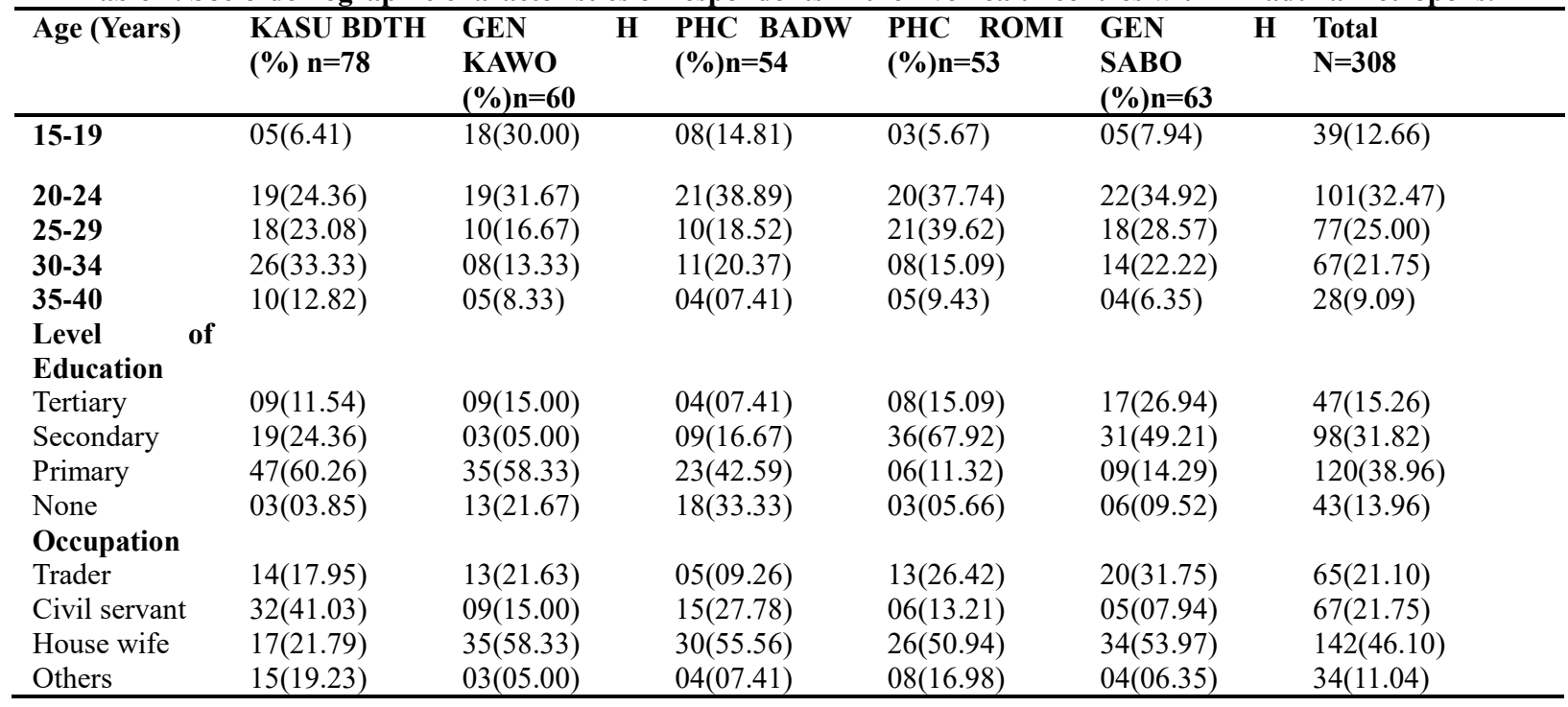


Table 2. Mosquitoes encountered within 30 house-holds around the five selected PHC within Kaduna metropolis

\begin{tabular}{llll}
\hline $\begin{array}{l}\text { Location } \\
\text { N=30 }\end{array}$ & $\begin{array}{l}\text { Culex } \\
\text { species }\end{array}$ & $\begin{array}{l}\text { Anopheles } \\
\text { species }\end{array}$ & $\begin{array}{l}\text { Aedes } \\
\text { species }\end{array}$ \\
\hline KASU BDTH & $30(11.6)$ & 0 & $33(38.8)$ \\
GENH KAWO & $53(20.5)$ & 0 & $16(18.8)$ \\
PHC BADW & $47(18.2)$ & 0 & $17(20.0)$ \\
PHC ROMI & $65(25.1)$ & 0 & $9(10.6)$ \\
GENH SABO & $64(24.7)$ & 0 & $10(11.8)$ \\
& & & $85(24.7)$
\end{tabular}

Keys: KASU BDTH = Kaduna State University (Barau Dikko) Teaching Hospital, GENH KAWO = General Hospital Kawo, PHC BADW = Primary Health Care Badarawa, PHC ROMI = Primary Health Care Ang. Romi, GENH SABO = General Hospital Sabon Tasha, N=30 (30 house-holds from the five areas) Six consenting house-holds each which are at within 3-km radius of each of the PHC or hospital were sampled for both adult and larvae mosquito species.

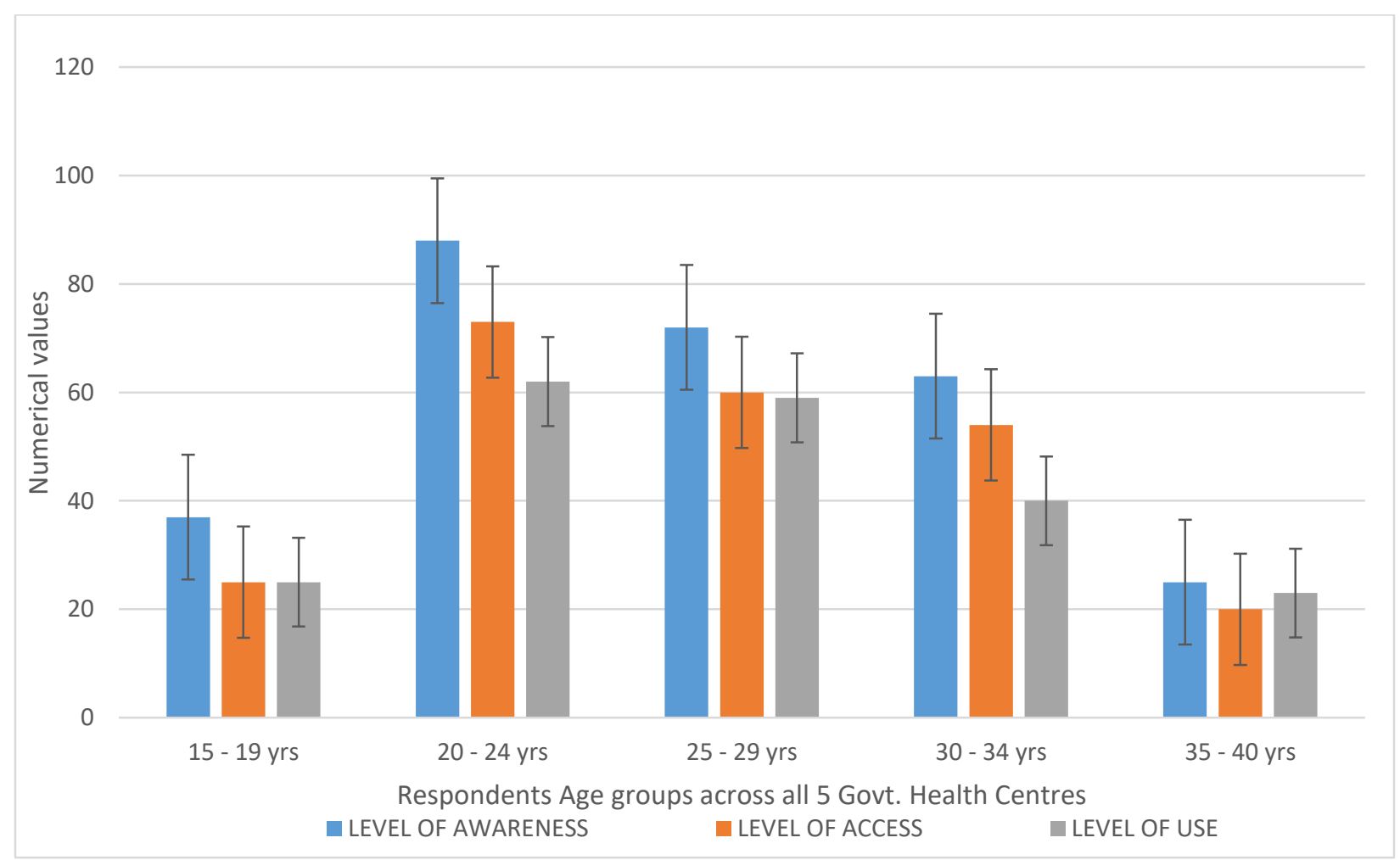

Fig. 1: Age group of all respondents in relation to level of awareness, access and use of LLINs in the 5 government. health centres. 


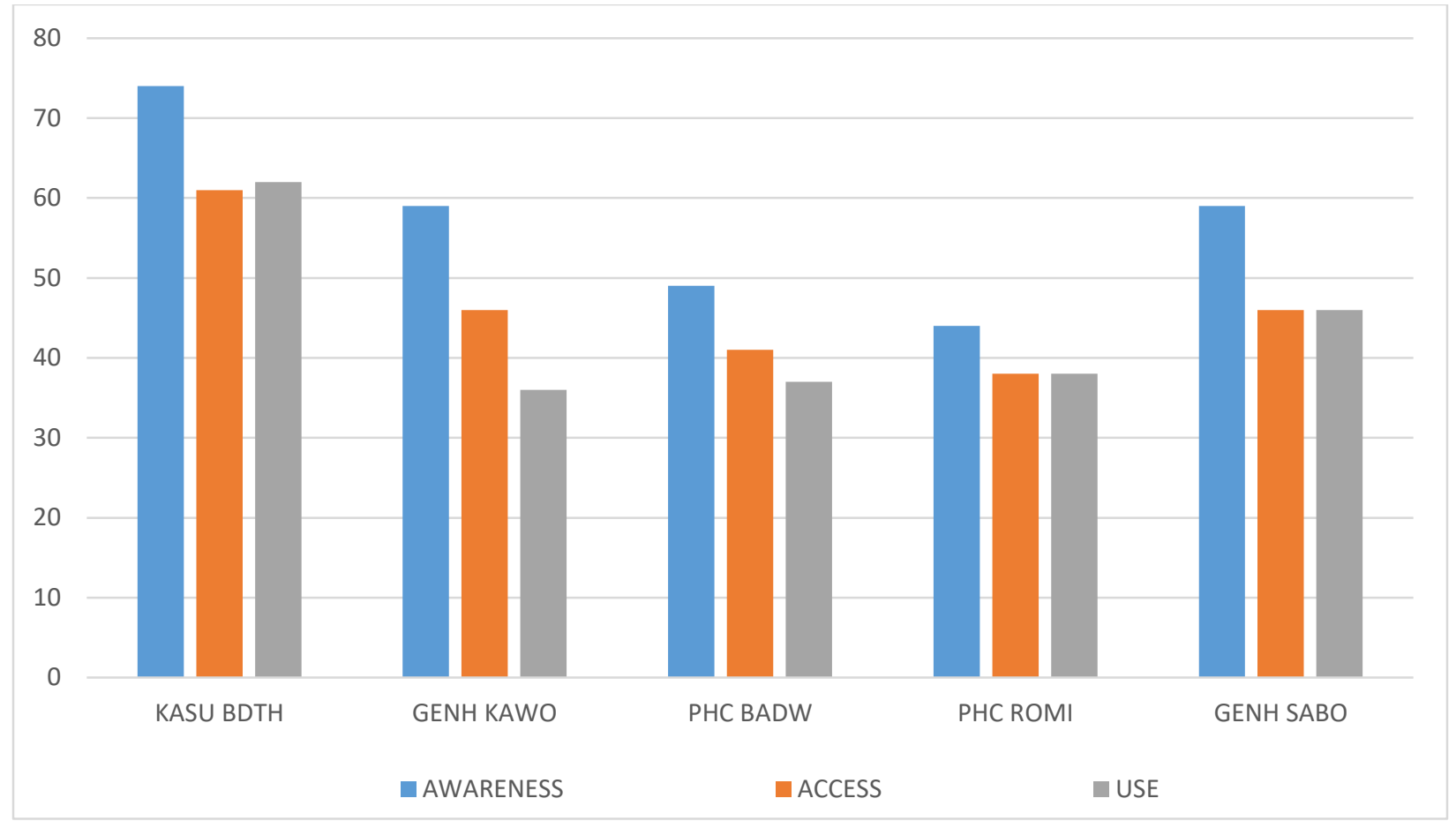

Fig. 2 Level of Awareness, Access and Use of long lasting insecticidal nets (LLINs) among pregnant women attending ante natal care in five selected health care facilities in Kaduna metropolis.

Mosquito samples were collected in 30 randomly selected households of the consenting pregnant women that were within three kilometer radius range of any of the antenatal clinic for 12 weeks period, (Table 2). A total of 344 larvae samples were encountered and identified using taxonomic keys and guide of Hopkins; Gillies and Coetzee. Aedes aegypti (24.7\%) occurred in 27 house-hold, while Culex quinquefaciatus (75.3\%) was encountered in all the 30 households.

\section{DISCUSSION}

The majority of the respondents overall awareness level observed in the study shows that most of the pregnant women attending antenatal care in all the five health centres have been adequately informed of the function and importance of LLINs during pregnancy. Talipouo et al.,(2019) reported similar $(94 \%)$ result in a study conducted at Yaounde, Cameroun. The result from the current study shows an improvement over the $82.6 \%$ awareness level reported in the study of LLINs among pregnant women in 18 Nigerian states; Ezire et al., (2015). It is also similar to the awareness level of $92 \%$ observed in the study of LLINs use among pregnant women attending ANC at Imo State University Teaching Hospital (IMSUTH) Orlu, Imo State by Eberendu \& Ozims, (2014). The high awareness level could be attributed to the education level of the respondents where $86 \%$ are literate. This was the case as reported by Nwoke et al., (2017) where awareness and use of insecticide treated nets (ITNs) in Imo state was influenced by the high education level. Though when awareness and educational status were compared using one way ANOVA, there was no significant difference $(\mathrm{P}>0.05)$. It had been emphasized that in northern Nigeria, low education level amongst other factors contributes highly to non-use of LLINs. The most important determinants for use of ITNs include literacy level, socio- economic status (SES), family size and structure, (Oyekale et al., (2013) and Onah et al., (2017). According to National Malaria Indicator Survey (NMIS) conducted between October to December 2010 at Sokoto by Kilian et al.,, failure to use available nets and lack of knowledge about malaria prevention are important determinants of malaria risk. Despite the ownership of LLIN in households, NMIS reported that only $49 \%$ of people used them the night before the survey and the use extended to only $50 \%$ of children, (Kilian et al., (2010). When asked about various ways to avoid getting malaria, only $17 \%$ of women answered "using ITN or LLIN" while $80 \%$ of women cited "using insecticide spray" and "eliminating stagnant water around living areas", respectively.

The general level of access to LLINs $(75.32 \%$,) by the respondents across the five health centres implies that LLINs are available in majority of Primary Health Centres within kaduna metropolis for access by pregnant women. This, by extension should help reduce malaria burden if used correctly. Also, a study in Lagos State, Nigeria by Umeh et al., (2012) reported access level to be $91.0 \%$; their research suggests that the success to high level of access to LLINs was due to the routine national LLINs distribution and implementation coverage Okeibunor, et al., (2012). The updated National Malaria Strategic Plan (NMSP) advices on access and ownership of at least two LLINs per house-hold; thus increasing LLINs use in Nigeria to $80 \%$, (FMoH, 2014). In this present study, the p-value for access to LLINs is 0.944 ( $\mathrm{p}>$ $0.05)$, this indicates that there is no significant difference in access to LLINs among pregnant women attending the health care facilities.

The relative average level $(67.86 \%)$ of use of LLINs in this 
study suggests that though awareness and access are high; it does not culminate to use by the owners to reduce or prevent malaria. There are factors which owners suggest that are responsible for non-use or low use of LLINs. Therefore, as speculated by some studies; the level of Useage as compared with Awareness or Access can be attributed to the non-challant attitude of humans generally, (Obol et al., 2013). A very low $(27.6 \%)$ level of use was reported by Awosan et al., (2013) in Sokoto and 39.1\% in Enugu by Ugwu et al., (2013). There was a dramatic difference in "Knowing or being Aware of the importance of LLINs and the Use"; Ezeigbo et al., (2016) reported on ITNs Ownership and Use in control of Malaria in Abia state; that out of the $77 \%$ which affirmed they have knowledge of LLINs only $38.6 \%$ actually owned and used the ITNs at least 4-5 times a week. This was also revealed by Ikealo et al., (2017) from Akwa, Anambra state where 99.1\% know about the importance and use of LLINs, only $80.4 \%$ own a LLINs and only $49.6 \%$ use nets once in 2 or 3 days, giving several reasons for non-use. LLINs can reduce malaria transmission by at least $60 \%$ and child deaths by $20 \%$ (Wagbasoma \& Aigbe, 2010; Okoye and Isara, 2011). The use of LLINs in some research carried out in Uganda shows that when compared with a situation when no net was used, there was increase in mean birth and placental parasitaemia (Mbonye et al., 2006). Analysis revealed that, average level of use of LLINs has the $p$-value of $0.463(p>0.05)$; thus no significant difference in the use of LLINs by pregnant women attending the health care facilities.

The major reason for non-use was discomfort caused by net use ranging from excessive heat or weather condition, chemical smell, color of net, mystical taboos, stress of use, torn nets and others, (Binka \& Adonge, 1997; Olajide et al., 2011 and Patel et al., 2012). There is need for health education to encourage pregnant women and dispelled their fears of chemicals used in treating nets (Ugwu et al., 2013; Obembe et al., 2014).

Of all the mosquitoes collected $75.3 \%$ were identified to be of the Culex genus and $24.7 \%$ were of genus Aedes, (Table 2). The presence of Culex and Aedes species in and around each of these PHCs agrees with the report of the presence of these two genera in various areas of the state, (Suleiman, 2012; Yayock et.al., 2014). Culex genera (75.3\%) suggest that residents are exposed to diseases such as Lymphatic filariasis and possibly yellow fever transmitted by Aedes species.

\section{CONCLUSIONS}

The study found out that majority of the respondents (92.53\%) are aware and have been adequately informed of the functions and importance of LLINs during pregnancy in reducing malaria disease. The access to LLINs by the respondents across the five health centres was quite appreciable $(75.32 \%)$, meeting the WHO standard of $75 \%$ and above for access to nets. The respondents that were encountered who actually use LLINs were $67.86 \%$. This study found no relationship between the age of pregnant women, educational level, level of awareness, access or use of LLINs; all the aforementioned factors are not contributing to the increase or decrease to one or another. Mosquito species encountered were Culex $(75.3 \%)$ and Aedes species $(24.7 \%)$ in and around all the five study areas where the research was conducted.

\section{RECOMMENDATIONS}

1. The State should ensure accessibility to free or subsidized Long Lasting Insecticidal Nets (LLINs) in the Primary Health Care centers and malaria drugs must be guaranteed.

2. There is need for implementing additional sensitization approaches especially the social media (Facebook, WhatsApp, YouTube, Text messages) to reach more people.

\section{REFERENCES}

ACHI, (2015). Archdiocesan Catholic Health Care Initiative; Christian Group distributes 15,000 Mosquito Nets to Kaduna LG. $\quad$ https://www.pressreader.com/nigeria/dailytrust/20150428/282037620712572. Retrieved $24^{\text {th }}$ May 2019.

Adebote, D.A., Oniye, S.J., Ndams, S.I. and Nache, M. (2006). The breeding of Mosquitoes (Diptera: culicidae) in Peridomestic Containers and Implication in Yellow Fever Transmission in Villages around Zaria, Northern Nigeria. Nigeria Journal of Entomology, 3:180-188.

Adeogun, A.O., Olojede, J.B., Oduola, A.O and Awolola, T.S. (2012). Efficacy of a Combination of Long Lasting Insecticidal Net (PermaNet 3.0) against Pyrethroid resistant Anopheles gambaie s.s and Culex quinquefasciatus: An experimental Hut Trial in Nigeria. Nigerian Journal of Clinical Biomedical Research. 6.1;37-50.

Anonymous, (2018): Leadership newspaper: Nigeria: Malaria FG to Distribute $14.4 \mathrm{~m}$ Nets Adewole 12th August, 2018 Leadership e-newspaper. Retrieved $5^{\text {th }}$ September,2018. https://allafrica.com/stories/201808120196.html)

Awosan, K., Ibrahim, M.T.O., Alayande, M.O., Isah, B.A., Yunusa, E., and Mahmud, M.B. (2013). Prevalence and barriers to the use of insecticide treated nets among pregnant women attending ante-natal clinic at specialist hospital Sokoto, Nigeria. Journal of Public Health and Epidermatology.

Binka, F.N. and Adonge, P. (1997). Acceptability and use of insecticide impregnated bed nets in Northern Ghana. Tropical Medicine and International Health, 2:419-507.

Corbel, V., Chabi, J., Dabire, R.K., Etang, J., Nwane, P., Pigeon, O., Akogbeto, M. and Hougard J.M. (2010). Field Efficacy of a New Mosaic Long Lasting Mosquito Net (PermaNet 3.0) against Pyrethroid-resistant Malria Vectors: a multi-centre study in western and central Africa. Malaria Journal/9/113 https://www/malaria.com/content/9/1/113

Eberendu, I.F. and Ozims, S.J. (2014). Awareness, Ownership and Utilization of Long Lasting Insecticidal Net (LLIN) Among Pregnant Women Attending Antenatal Clinic in Imo State University Teaching Hospital Orlu, Imo State. International Journal of Research in Medical and Health Sciences. https://www.ijsk.org/ijrmhs.html. Retrieved 2Feb. 2017 
Ezeigbo, O. R., Ejike, E. N and Nwachukwu I. (2016). Insecticide-Treated Bed Net [ITN]: Ownership and Useage in the Control of Malaria in Abia State, Nigeria. American Journal of Epidemiology and Infectious Diseases .4:3:42-46: Doi:10.12691/ajeid-431

Ezire, O., Adebayo, S.B., Idogho, O., Bamgboye, E.A and Nwokolo E. (2015). Determinants of Use of Insecticide-treated Nets among Pregnant Women in Nigeria. International Journal of Women's health. 2015; 7: 655-661. https://ncbi.nlm.nih.gov/pmc/articles/PMC4492654. Accessed 27 December 2017

Federal Ministry of Health. (2013). Nigeria National Malaria Control Strategic Plan 2009-2013. Abuja: Nigeria Malaria Control Programme; 2009.

Federal Ministry of Health. (2014). Nigeria National Malaria Control Strategic Plan. Abuja: Federal Ministry of Health; 2014.

Gillet, J.D. (1972). Common African Mosquitoes and their medical importance. William Heinemann medical books limited, London Press, pp 236.

Gillies, M.T and Coetzee, B.A. (1987). "Supplementary to Anophelinae of Africa, South of Sahara (Afro-Tropical Region)". Publication of the South Africa Institute of Medical Research, . 55, 1987, pp. 1-143.

Global Fund, (2018). Data and statistics taken from: Global Fund Nigeria country profile webpage https://www.theglobalfund.org/en/portfolio/country/?loc=NGA $\& \mathrm{k}=430 \mathrm{~b} 8 \mathrm{acd}-\quad$ ef36-4ef1-Accessed August 16, 2018.

Hopkins, G.H.E. (1952). Mosquitoes of Ethopian region, larval bionomics of mosquitoes and taxonomy of culcline larvae. $2^{\text {nd }}$ edition. Adlard and sons Ltd. London. 78:307-318.

Ikealo, L.C., Azuike, E.C., Njelita, I.A., Nwachukwu, C.C., Okafor, K.C., Nwosu, C., Agbanu, C. M and Ofomata, U.C. (2017). Insecticide Treated Nets: Perception and Practise among Pregnant women Accessing Ante-nal Services at a Tertiary Hospital in Akwa, Nigeria. MOJ Public Health 5 (4): 00135 Doi: 10.15406/moiph2017.05.00135.

Kilian, A., Opawale, A., Zegers-Beyl, C., Baba, E. and Boulay, M. (2010). Evaluation of the Integrated LLIN distribution and child health campaign of December 2009, Sokoto, Nigeria. Retrieved 17 feb. 2018 http://www.allianceformalariaprevention.com/documents/sokot o\%20final\%20rep ort $\% 20$

Lim, S., Fullman, N., Stokes, A., Ravishankar, N., Masiye, F. and Murray, C.L. (2011). Net benefits: a multi-country analysis of observational data examining associations between insecticide-treated mosquito nets and health outcomes. PLoS Medical. ;8:e1001091.

Malaria Control Unit Kaduna, (2017). Report on Malaria Control and Nets Distribution. Malaria Control Desk Officer; Personal Communications. Kaduna State Ministry of Health, Kaduna, Nigeria.
Mbonye, A. K., Neema, S. and Magnussen, P. (2006). Preventing Malaria in pregnancy: A study of perceptions and policy implication in Mukono district, Uganda. Health Policy Journal 21: 17-26.

Ndabula, C., Jidauna, G. G., Averik, P. D., Oyatayo, T. K., Abaje, I. B., Andesikuteb, A. Y. (2014). Characterization of Sprawling in Kaduna Metropolitan Area. American Journal of Environmental Protection. 3 (3), 131-137. Doi:10.11648/j.ajep.20140303.14

NMETS, (2016). Nigerian Metrological Society: Conference Theme: "Climate Variability and Change: Impact, Science, Innovation and Policy" Conference Abstract Proceedings, At Federal University of Agriculture, Abeokuta: $21^{\text {st }}-24^{\text {th }}$ November, 2016.

Nwoke, E. A., Eze C. and Ibe, S.N.O. (2017). Awareness and the Use of Insecticide Treated Nets for Malaria Control in Amainyi, Ihitte-Uboma Lga, Imo State, Nigeria. International Journal of Science and Research Methodology 6 2. 15pp. https://ijsrm.humanjournals.com/wp Retrieved 25 Sept 2019.

Obembe, A., Anyaele, O.O. and Oduola, A.O. (2014). Lessons from the implementation of LLIN distribution campaign in Ilorin Kwara State, Nigeria. Biomed Central Public Health, Retrieved 2017, February, 20. http://www.ncbi.nim.gov.

Obol, J.H., Ononge, S. and Orach, C.G. (2013). Utilization of Insecticide-Treated Net Among Pregnant Women in Gulu: A Post Conflict District in Northern Uganda. African Health Sciences; 13: 962-969. Doi: 10.4314/ahs.v13i4.15. Accessed 27 December 2017.

Okeibunor, J.C., Orji, B.C., Brieger, W., Ishola, G., Otolorin, E., Rawlins, B., Ndekhedehe, E.U., Onyereho, N. and Fink, G. (2012). Preventing malaria in pregnancy through communitydirected interventions from Akwa Ibom state, Nigeria. Malaria journal. 10 :227-10. 1186/1475-2875-10-227.

Okoye, C.A. and Isara, A.R (2011). Awareness on the use of Insecticide treated nets among women attending attending ANC in Etsako West LGA, Edo state. Nigeria JournalClinical Practice. 13 (2):144-148.

Olajide, F.O., Afolabi, O.T and Omomuniniyi, O.A. (2011). Challenges with the use of Insecticide Treated Nets Among Pregnant Women in Ife-Ijesha Zone, South Western Nigeria. Journal of community medicine and primary health care, 25: 1 \& 2 .

Onah, I.E., Adesina, F.P., Uweh, P.O and Anumba, J.U. (2017): Challenges of Malaria Elimination in Nigeria; A Review. International Journal of Infectious Disease and Therapy, 2 (4) 79-85 Doi: 10.11648/j.ijidt.20170204.14

Oyekale, A.S., Lawal, O. and Onu, M.E. (2013). Non-income Assessment of Poor Growth and Programmes in Nigeria. Policy Briefs, GP_No. 04, July, African Economic Research Consortium (AERC), Nairobi, Kenya. 
Patel, E.K., Gupta, A. and Oswal, R.J. (2012). A review on: Mosquito repellent methods. International Journal of Pharmaceutical, Chemical and Biological Sciences, 2 (3):310317.

Service, M.W. (1976). Mosquito Ecology: Field Sampling Methods. Applied Science Publishers Ltd. London pp 583 Suleiman, J.A. (2012). A Survey of Indoor-resting Population of Mosquitoes in some areas of Kaduna Metropolis, Nigeria. Online Journal and information Portal of Life Sciences. http://biopathways.blogspot.com/2012/07/survey-of-indoorresting-population- of.html. Accessed 28 December 2017.

Talipouo, A., Ngadjeu, C.S., Belisse, P.D., Djonkam, L.D., Chiana, N.S., Kopya, E., Bamou, R., Ambene, P.A., Woromogo, S., Kekeunou, S., Wondji, C.S. and Nkondji, C.A. (2019). Malaria prevention in the city of Yaoundé: knowledge and practices of urban dwellers. Malaria Journal 18:167 https://doi.org/10.1186/s12936-019-2799-6. Retrieved 24th March 2020.

Umeh, U.A., Obi, S.N., Onah, H.E., Ugwu, E.O., Ajah, L.O. and Umeh, C.R. (2012). The impact of intermittent preventive treatment with sulphadoxine-pyrimethamine on the prevalence of malaria parasitemia in pregnancy. Tropical Doctor Journals, 42:133-5.

Ugwu, E.O., Ezechukwu, P.C., Obi, S.N., Ugwu, A.O. and Okeke, T.C. (2013). Utilization of insecticide treated nets among pregnant women in Enugu, South Eastern Nigeria. Nigeria Clinical Practice; 16:292-6

Wagbasoma, V.A. and Aigbe, E.E. (2010). ITNs Utilization among pregnant women attending ANC in Etsako West LGA, Edo state. Nigeria Journal Clinical Practice. 13 (2):144-148. WHO, (2005). Resolution WHA58.2 on malaria control. Fiftyeighth World Health Assembly, Geneva: World Health Organization; 2005 (see document WHA58/2005/REC/1, http://apps.who.int/gb/ebwha/pdf files/WHA58-

REC1/english/A58 2005 REC1-en.pdf, accessed 10 March 2017)
WHO, (2008). World Malaria Report 2008. Geneva: WHO. http://whqlibdoc.who.int/publications/2008/9789241563697_e ng.pdf

WHO, (2016). World Malaria Report (2016). Geneva: World Health Organization, 2016.

http://www.who.int/malaria/publications/world-malaria-report2016/report/en/ Accessed 23 October, 2017.

WHO, (2017). WHO fact sheet. www.who.int/malaria/media/factsheets qa/2017/en.

WHO, (2018). Insecticide-treated nets to reduce the risk of malaria in pregnant women.

http://www.who.int/elena/titles/bednets_malaria_pregnancy/en/

WHO, (2019). World Health Organization; World Malaria Report 2019, Geneva.

https://creativecommons.org/liecenses/by-nc-sa/3.0/igo.

Retrieved $4^{\text {th }}$ December, 2019.

Yayock, H.C., Ndams, I.S., Kogi, E., Ahmed, A.B. \&Vagime, C.G. (2014). Distribution of mosquito Species in Kaduna Metropolis, Kaduna State, Nigeria.

https://researchgate.org/publication/28472005-Distribution-ofmosquito-species-in-kaduna-metroolis-kaduna. Accessed 29 December 2017.

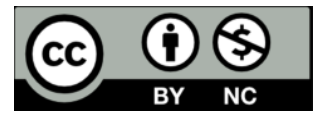

(C)2020 This is an Open Access article distributed under the terms of the Creative Commons Attribution 4.0 International license viewed via https://creativecommons.org/licenses/by/4.0/ which permits unrestricted use, distribution, and reproduction in any medium, provided the original work is cited 